\title{
Algunas incógnitas, precisiones e incertidumbres sobre la vida y la muerte de Alonso Álvarez de Soria ${ }^{1}$
}

\author{
José Manuel Rico García \\ Universidad de Huelva \\ Departamento de Filología \\ Facultad de Humanidades \\ Campus del Carmen \\ Avda. de las Fuerzas Armadas, s/N \\ 21007 Huelva \\ josemanuel.rico@dfesp.uhu.es
}

[La Perinola, (IssN: 1138-6363), 22, 2018, pp. 247-269]

DOI: $10.15581 / 017.22 .247-269$

Para la historia literaria conocer las circunstancias y el año de la muerte de Alonso Álvarez de Soria no pasaría de ser una información útil y anecdótica, si no fuera porque de tales datos depende uno de los asuntos más controvertidos de la literatura áurea, la fecha de composición ${ }^{2}$ del Buscón. Casi de modo unánime e invariable se ha repetido que el término a quo para la redacción del relato es la referencia histórica de la muerte del poeta y hampón sevillano, acaecida, según la opinión mantenida por Rodríguez Marín en su biografía del poeta ${ }^{3}$, a finales de 1603 o al comienzo de 1604. El distinguido cervantista fundó su hipótesis sobre el conocimiento incompleto e incierto de los hechos; sin embargo, se le ha concedido valor real referencial, como si fuera un hecho probado $\mathrm{y}$, por consiguiente, incuestionable ${ }^{4}$.

1. Este trabajo se enmarca en la línea de investigación del proyecto Vida y escritura, 1 (FFI2015-63501-P), dirigido por el Dr. Luis Gómez Canseco y financiado por el Ministerio de Economía y Competitividad.

2. Para el conocimiento exacto, completo y actualizado de la cuestión, véase el ponderado análisis de Cabo Aseguinolaza, 2011, pp. 181-202. Se manifiesta con atinada discreción al tratar sobre la fecha de la muerte de Alonso Álvarez: «lo único que cabe aseverar es que ocurrió con posterioridad al 26 de junio de 1603, fecha en que tomó posesión de su cargo el Conde, y antes de 1609, cuando fue sustituido» (Cabo Aseguinolaza, 2011, p. 411).

3. Rodríguez Marín, 1901, pp. 193-198.

4. Basta considerar la opinión de Lázaro Carreter (1961, p. 320), para quien había «dos datas inequívocas del libro: septiembre de 1604, fin del sitio de Ostende, y 16031604, ejecución de Alfonso Álvarez, el Tuertom. Díaz-Migoyo, 1980, p. 174, que ha estudiado concienzuda y atinadamente el problema de las fechas del Buscón, sostenía que la referencia temporal que «permite avanzar más la fecha a quo de su composición es 
Las indagaciones realizadas en el Archivo Histórico Provincial de Sevilla (AHPS) y en otras fuentes documentales no permiten demostrar lo contrario ni, mucho menos, verificar la fecha de su muerte; pero sí conceden, al menos, que se puedan plantear algunas incógnitas sobre la existencia de Alonso Álvarez de Soria y que sea posible cuestionar algunos episodios de su sucinta biografía que se tienen por ciertos.

\section{Noticia de los primeros testimonios sobre la muerte de Alonso Álvarez}

En general, se ha aceptado como probada la muerte de Alonso Álvarez de Soria en la horca entre el veintiséis de junio de 1603, fecha de la toma de posesión como asistente de Sevilla de Bernardino González Delgadillo y Avellaneda, quien ordenó su ejecución, y los primeros meses de $1604^{5}$. Inopinadamente, Méndez Bejarano ${ }^{6}$, sin aportar ninguna razón que justificara su determinación, la situó en 1609. Antes, Mérimée ${ }^{7}$, de forma igualmente arbitraria, la había fijado en 1607. Pero lo único cierto es que no hay ningún documento que pueda verificar la ejecución de Alonso Álvarez de Soria; esto es, en términos forenses, no hay evidencias de su muerte: solo han quedado testimonios literarios del suceso.

Hemos, pues, de preguntarnos de dónde procede esta creencia, el unánime crédito que se ha prestado a tal hecho como cierto. Para responder a esa cuestión conviene poner en orden cronológico las noticias de la vida del ruiseñor del hampa 8 tal y como nos las proporcionaron bibliógrafos, eruditos y polígrafos.

Nada se sabía de Alonso Álvarez de Soria hasta la publicación en 1863 del primer tomo del Ensayo de una biblioteca española de libros raros y curiosos de Bartolomé José Gallardo, que incluía en la entrada dedicada a Juan de Arguijo la transcripción de un fragmento de una Miscelánea $a^{9}$ del Archivo de la Catedral de Sevilla que recogía la primera

justamente esta de la muerte de Alonso Álvarez, ocurrida a finales de 1603 o principios de 1604. Las demás alusiones señaladas hasta el momento por la crítica carecen de fuerza determinativa a quo posterior a 1604».

5. Rodríguez Marín, 1901, pp. 196-199.

6. Méndez Bejarano, 1989, vol. 1, p. 24: «Fácil poeta y hombre de maleante condición, pereció ahorcado en 1609, según dicen, a causa de un feo apodo que puso al Asistente D. Bernardino de Avellaneda, si bien, aunque esta fuera la causa, otro fue el pretexto».

7. Mérimée, 1886, p. 151: «Le nomquinous reporte à la date la plus récente, croyons-nous, estcelui du poète Alonso Álvarez, à la mémoireduquelboivent les Valientes de Séville. Cet Alonso Álvarez futexecuté à Séville, en 1607, sur les ordres de l'Assistant, le comte du Castrillo (surnomméCaga-la-Soga), le que lo ccupait déjà cette charge en 1606». El dato del nombramiento del asistente es inexacto, como se ha dicho, tomó posesión del cargo el 26 de junio de 1603. Ese error pudo inducir a Mérimée a creer que la ejecución de Álvarez de Soria fue en 1607.

8. Con este feliz sobrenombre designó Lara Garrido (1987) a Alonso Álvarez de Soria en la mejor monografía y edición de sus poemas.

9. Gallardo, 1863, cols. 285 y 286. Describe el manuscrito esquemáticamente: “Miscelánea.-Archivo Catedral de Sevilla, en $4^{\circ}$. MS original, l. de principios del siglo XVII") 
semblanza del poeta. Allí se decía de él que había sido el creador de la primera copla de pie quebrado «que se oyó en Sevilla» y que era hijo de un jurado de la collación de San Vicente, dato confirmado documentalmente por Rodríguez Marín en 1901. Añadía el texto de la Miscelánea algunos detalles fundamentales sobre las causas y las circunstancias de su muerte:

murió colgado en el aire, porque un asistente de Sevilla, que era el conde de Castrillo, irritado de que en público burlaba dél, le anduvo a la mira, y por una cosa bien ligera de una cuestión que armó le sacó de la iglesia de Santa Ana y le acusó que llamaba este al asistente por mal nombre Caga la Soga, tomándolo de un hombre pobre... ${ }^{10}$

La noticia trasladada por Gallardo no precisa la fecha del ahorcamiento, que hubo de ser entre 1603 y 1609, durante el periodo que Bernardino de Avellaneda desempeñó el cargo de asistente. Se deduce también que fue redactada muchos años después de acontecido el suceso, pues a don Bernardino le concedieron el título de conde de Castrillo en 1610, después de que cesara como asistente. Además, el autor del texto de la Miscelánea le atribuye «según común opinión, la copla de pie quebrado que le envió a D. Rodrigo Calderón avisándole de su mal fin » ${ }^{11}$. Evocaba esa información después de 1621, año de la ejecución del marqués de Siete Iglesias: «hubo la muerte y castigo en ella que en Madrid se vido» ${ }^{12}$. Por consiguiente, la Miscelánea no puede ser de principios del siglo xvII como sostuvo Gallardo en su descripción del códice. El propio Rodríguez Marín ya lo había advertido ${ }^{13}$. Lara Garrido creyó que del texto de la Miscelánea se deducía que la muerte referida de Rodrigo Calderón estaba “más o menos lejana» ${ }^{14}$, estimación que compartimos ${ }^{15}$ y que permiten presumir los datos externos e internos del manuscrito que hemos localizado en el Archivo de la Catedral de Sevilla que contiene el texto publicado por Gallardo. Este es uno de los apuntes de mano que se encuentran en un pequeño códice facticio, en cuarto y encuadernado en pergamino que se conserva en el Fondo Capitular, sección Ix (Fondo Histórico General) del mencionado Archivo de la Catedral de Sevilla (Acs). La signatura actual es Caja 11294, documento núm. 6. El primero de esos apuntes lleva por título Cuaderno misceláneo en cuarto con observaciones al libro que publicó el marqués de Estepa sobre las láminas que se hallaron en el Monte de Granada, fechado el 10 de mayo de

10. Gallardo, 1863, col. 286.

11. Gallardo, 1863, col. 286.

12. Gallardo, 1863, col. 286.

13. Rodríguez Marín, 1901, p. 198.

14. Lara Garrido, 1987, p. 35.

15. Recordaba también Lara Garrido (1987, p. 35) que ya Cotarelo (1886, p. 69) publicó una versión de esa copla con variantes que se atribuía al conde de Villamediana y que Rozas (1964, p. 51) había recensionado la atribución a Villamediana de la redondilla en los manuscritos de la BNE 10.293 (fol. 92r.) y 10.917 (fol. 92v.). 
1633; es decir, son unos escolios a la obra sobre las láminas plúmbeas de Adán Centurión, marqués de Estepa, Información para la historia del Sacro monte... (Granada, 1632). Sobre la propia portada en pergamino aparece como título Miscelánea y a lápiz la fecha de 1633. El manuscrito está compuesto por 7 documentos y 21 hojas, de distintas manos, las dos últimas son folios plegados en cuarto en el códice. El texto transcrito por Gallardo se corresponde con el apunte núm. 5, folio 17 r. y v. Además de aparecer el año de 1633 en la encuadernación, al lado del título, el documento núm. 6 lleva la fecha de 1635.

Cabe pensar que el relato de los hechos podría haberse visto alterado por el deficiente recuerdo de los mismos a causa del transcurso de los años. Nos parece bastante improbable, por ejemplo, que en torno a 1603 Álvarez de Soria pudiera profetizar la muerte en el cadalso de Rodrigo Calderón en la copla de pie quebrado que le adjudicaba la «común opinión». De este testimonio arranca también una idea desconcertante que ha sido asumida sin cuestionarse: el motivo de la condena fue haber motejado al asistente. El propio autor de la semblanza admite que la causa fue bien ligera $y$, a nuestro juicio, aceptarlo desafiaría la lógica de lo verosímil y de nuestro conocimiento de la realidad histórica; no parece posible, de acuerdo con las garantías procesales de la época, que la razón de la condena fuera el insulto proferido contra don Bernardino $^{16}$.

Tan leve, en apariencia, resulta el motivo de su detención y procesamiento que dos eminentes historiadores lo magnificaron para darle credibilidad, aunque para ello traspasaron los límites de lo acreditado; así, Ruth Pike y Bartolomé Bennassar, condicionados por la vida heroica fabulada por Rodríguez Marín, alteraron lo estrictamente conocido para convertir a Alonso Álvarez en un héroe de la rebeldía social contra los poderes públicos. Pike presumió que

una composición salida de su acre pluma (calumniosos insultos contra el entonces asistente de Sevilla, conde de Avellaneda) y su amistad con delincuentes e indeseables, le proporcionó una temprana muerte en la horca en $1603^{17}$.

16. La idea de que fue Álvarez de Soria quien puso a don Bernardino de Avellaneda el sobrenombre de Cagalasoga se ha repetido sin matices desde el testimonio recogido por Gallardo; pero lo cierto es que el apodo debió de convertirse en proverbial en la época y, por tanto, consabido de todos, hasta el punto de que Diego Duque de Estrada lo recordó sin empacho, sin aparente temor y sin mencionar a su hipotético inventor, en el manuscrito de sus difundidos Comentarios del desengañado de sí mismo, donde al narrar un siniestro suceso que protagonizó en Sevilla en 1608, escribe: «fue menester escapar de Sevilla, porque el Asistente y Corregidor, Don Bernardino de Avellaneda, que por mal nombre llamaban "Cagalasoga", me buscaba con grandes ansias" (Duque de Estrada, Comentarios, p. 110).

17. Pike, 1978, p. 117. 
Por su parte, Bennassar encareció aún más los rasgos subversivos del personaje:

Alonso Álvarez de Soria, el poeta-truhán, hijo de una rica familia de mercaderes conversos sevillanos, cuyas obras son gritos de revuelta contra el orden establecido y que fue ahorcado en 1603 a consecuencia de un panfleto insultante y calumnioso contra el conde de Avellaneda, corregidor de Sevilla ${ }^{18}$.

En el mismo primer tomo del Ensayo de una biblioteca de Gallardo se añadió como apéndice el trabajo de Aureliano Fernández Guerra Noticias de un precioso códice de la Biblioteca Colombina ${ }^{19}$, en el que daba a conocer un manuscrito inédito de la Biblioteca Capitular de Sevilla (вС 56-4-34) y donde el benemérito editor de Quevedo comentaba la relación atribuida a Cervantes titulada Carta a don Diego de Astudillo Carrillo en que se le da quenta de la fiesta de san Juan de Alfarache, el día de Sant Laureano, que se halla entre los folios 108 y 135v. En el comentario a una composición de cabo roto, obra de un tal Roque de Herrera, que recoge la crónica del certamen, Fernández Guerra parafrasea la noticia de Gallardo encontrada en la Miscelánea de la Biblioteca Capitular y añade un nuevo y relevante documento sobre el ruiseñor del hampa:

Es del todo ignorado y no sé que se imprimiera el siguiente Romance que Alonso Álvarez, poeta sevillano, hizo estando sentenciado a ahorcar por D. Bernardino, a quien puso por nombre Caga la soga: "Engañosa confianza."20.

A continuación, transcribía el citado romance y describía la fuente:

Hallábase en un códice en $8^{\circ}$, escrito hacia el año de 1630, todo él de poesías de Góngora, salvo unas cuantas de Quevedo, Mendoza y Juan de Salinas, a quien allí se califica de Tostado sevillano. Me ha permitido bizarramente disfrutar de este manuscrito su dueño, el sr. Sancho Rayón ${ }^{21}$.

El códice tuvo el mismo afortunado periplo que muchos de los que acabaron en la Hispanic Society of America, esto es, de Gallardo había pasado a Sancho Rayón, de quien fue a parar al marqués de Jerez de los Caballeros, de cuya biblioteca salió, tras su venta a Archer Milton Huntington en 1902, para ingresar en la citada institución en Nueva York. Se trata del manuscrito poético HSA в 2361, número cxLV del Catálogo de los manuscritos poéticos castellanos de la Hispanic Society

18. Bennassar, 1990, p. 223.

19. Gallardo, 1863, cols. 1245-1326. Un año después, en 1864, la misma imprenta y estereotipia de M. Rivadeneyra publicó el citado apéndice en un volumen autónomo con ligeros cambios en el título, Noticias de un precioso códice de la Biblioteca Colombina: algunos datos nuevos para ilustrar el «Quïote»; varios rasgos ya conocidos, ya inéditos de Cervantes, Cetina, Salcedo, Chaves y el bachiller Engrava.

20. Fernández Guerra, 1864, p. 20.

21. Fernández Guerra, 1864, p. 20. 
que realizaron Rodríguez Moñino y María Brey ${ }^{22}$; el romance ocupa en él los folios $177 \mathrm{v}-178 \mathrm{v}$, composición número 192 . El otro testimonio conocido del poema, editado por Lara Garrido ${ }^{23}$, se encuentra en el Cancionero antequerano y lo introduce un epígrafe más lacónico, que omite los pormenores sobre la causa de la sentencia: «De $A l^{\circ} A ́ l v a r e z$ c[an]do lo llevaron a ahorcars. En los cuarenta y seis versos del romance no hay ninguna alusión a la horca ni a los motivos de la ejecución, se trata de un poema penitencial, en el que Alonso Álvarez da muestras de real o fingida contrición. Los detalles del epígrafe que encabeza el romance en el manuscrito de la Hispanic Society coinciden con el relato de la Miscelánea, de tal manera que cabría pensar que lo añadió Gallardo, que fue poseedor del manuscrito y que conocía de antemano los datos proporcionados por la Miscelánea.

Tampoco creemos probable que los excelentes versos del romance, que expresan con honda emoción el sentimiento ejemplarizante de salvación espiritual de quien va a ser ejecutado, fueran compuestos en el último suspiro, ante la amenaza inminente de estar frente al verdugo. Las ejecuciones eran actos tan cotidianos y se habían trivializado de tal manera que en la cárcel de Sevilla fueron frecuentes los juegos en que se simulaban el desfile del ajusticiado y se fingían ahorcamientos ${ }^{24}$. Tan naturales resultaban estos juegos en la sociedad de la época que los anales y avisos ${ }^{25}$ de la ciudad relatan la muerte en 1604 de un niño mientras se entretenía con otros en el macabro juego de los ahorcados. Algunas jácaras de Quevedo ${ }^{26}$ representan la literaturización de esa familiaridad con la muerte, la actitud irreverente e incrédula de los jaques que relatan desde la cárcel su existencia y su final ante el cadalso, o refieren, en parecidas circunstancias, los momentos previos a «ensabanar / sus bienes y su persona» ${ }^{27}$. En su de profundis particular, Álvarez de Soria verbalizó, en nuestra opinión, no la experiencia real y precipitada de su ajusticiamiento, sino su destino probable, enunciado a través de

22. Rodríguez Moñino y Brey, 1965. Según la descripción de Rodríguez Moñino, el libro está en cuadernillos sueltos y tiene letra de la primera mitad del siglo xvir. Hay en él una nota de Gallardo que indica su procedencia: «Regalome este códice en Castro el Caballero Mazuelo (El Ciego)».

23. Lara Garrido, 1987, p. 75; ocupa los fols. 29r.-30r. del ms. м6, II de la Biblioteca de la Caja de Ahorros de Antequera, el llamado Cancionero antequerano.

24. Véase un análisis detallado de estos juegos macabros, realizado a partir de las memorias del Padre León, consejero espiritual de la cárcel real de Sevilla, en Herrera Puga, 1971, pp. 125-129.

25. Lo recogen, por ejemplo, las Noticias y casos memorables..., fol. 34.

26. Así sucede en el final de la Carta de la Perala a Lampuga, su bravo (Blecua, núm. 851), donde la daifa relata a Lampuga, que espera la horca, cómo murió Lumbreras, “con un poquito de credo / sin sermón y sin desmayo» (vv. 84-85). Villagrán refiere los tormentos sufridos en la jácara que comienza «Mancebitos de la carda» (Blecua, núm. 853), y mismo tenor tiene la Relación que hace un jaque de sí y de otros (Blecua, núm. 856).

27. Son los versos 3 y 4 de la jácara quevediana Postrimerías de un rufián (Blecua, núm. 862), en la que Gorgolla, con el cuerpo descosido, discurre sobre su existencia en el lecho de muerte. 
un sujeto lírico reconocible y avalado por la poesía germanesca, aunque con un tono de sincera aflicción del que aquella carecía y que le proporcionaba a su romance un singular sesgo moral, real o fingido, ajeno a los romances jácaros.

En 1866, en el tomo segundo del Ensayo de una biblioteca, Gallardo editó numerosas piezas de los manuscritos 56-3-4 y 56-3-5 de la Biblioteca Capitular y Colombina que contienen las Obras de Juan de la Cueva; entre ellos el soneto «No des al febeo Álvarez la muerte, /oh, gran don Bernardino, así te veas» (вс 56-3-4, fol. 119r.). Al frente del soneto aparece con la misma letra el siguiente epígrafe: «A don Bernardino de Avellaneda, Asistente de Sevilla, queriendo ahorcar a Alonso Álvarez de Soria ${ }^{28}$. El contenido del soneto está en perfecta consonancia con lo que en ese momento se sabía del poeta rufián. Los versos tienen como enunciatario a don Bernardino de Avellaneda, a quien se suplica para que se compadezca del (febeo Álvarez) y convierta su odio personal en piedad. También apela a la justicia poética para que ejecute su sentencia, pues su jurisdicción y autoridad dependía de Apolo y no del asistente: «De ese que tienes preso el dios Apolo / es su juez y no sufragáneo tuyo» (vv. 9 y 10). El soneto tiene plena coherencia con la realidad histórica, porque los asistentes tenían la facultad de poder conmutar las penas, y esa es la solicitud que resume el sentido global del poema.

Atinadamente observó también Lara Garrido cómo los versos delataban las presiones de voces ajenas para que se consumara la pena capital: “cierra el oído, ciérrale, no creas / al vano adulador que te divierte» (vv. 7 y 8). El códice que lo contiene, rubricado en 1603 y probablemente concebido para la imprenta, es un autógrafo de Juan de la Cueva que incluye la mayor parte de su corpus lírico. Recoge poemas compuestos entre 1567 y 1609, porque es, en palabras de José María Reyes Cano, un códice “'vivo, en el sentido de que le debió acompañar toda su vida y en el que trabajó a lo largo de los años» ${ }^{29}$. Ningún indicio hay en el poema ni en el manuscrito que permita fecharlo. Su composición debió de coincidir con los hechos y, por tanto, lo escribió en Sevilla, antes, desde luego, de su estancia en Cuenca, adonde se trasladó en 1608.

Las informaciones registradas en los dos tomos del Ensayo de Gallardo resultaron suficientes a Lasso de la Vega para redactar con ellas una ceñida bio-bibliografía del poeta y darle una entrada en el catálogo de los poetas sevillanos de los siglos XVI y XVII que insertó en su Historia y juicio crítico de la escuela poética sevillana ${ }^{30}$. Fue muy cauto al pronunciarse sobre la fecha de la muerte: «El suplicio de este des-

28. Gallardo, 1866, col. 679. El epígrafe recoge el nombre completo del poeta. En los demás testimonios (salvo en protocolos que se examinan más adelante) es referido como Alonso Álvarez.

29. Reyes Cano, 2009, p. 334.

30. Lasso de la Vega, 1871, pp. 181-184. 
graciado debió tener lugar antes del año de 1609, en el que dejó de ser asistente de Sevilla don Bernardino de Avellaneda» ${ }^{31}$.

\section{EL LOAYSA DE “EL CELOSO EXTREMEÑO»: LOS DOCUMENTOS PARA LA BIO- grafía novelada de Rodríguez Marín. Algunos datos nuevos}

Durante las vacaciones de 1899 concibió Rodríguez Marín la idea de escribir un estudio acerca de Alonso Álvarez de Soria, quien, en su opinión, había inspirado el personaje cervantino del Loaysa en El celoso extremeño; así se lo comunicó a Menéndez Pelayo en carta fechada en el verano de 1899:

En estas vacaciones, más cortas de lo que conviene a la salud de mis hijos y a mi descanso, prepararé un librillo acerca de quién fue el Loaysa de $E l$ celoso extremeño [...] creo que el Loaysa es, ni más ni menos, el infortunado poeta sevillano Âlonso Álvarez de Soria: el tuerto Alonsillo ${ }^{32}$.

El 29 de agosto le respondía don Marcelino desde Santander celebrando su conjetura.

Con la percepción íntima de que el Loaysa cervantino era el trasunto del poeta, Rodríguez Marín acometió una biografía formada por la sucesión cronológica de materiales documentales dispersos que su conocimiento de la historia literaria y su imaginación procuraron unir coherentemente para llenar y comprender los perfiles más destacados de toda una vida. $Y$, ciertamente, la biografía que elaboró el polígrafo ursaonense no está exenta de componentes fantásticos, hay en ella demasiadas conjeturas; pero fue la primera contribución documental sobre el poeta y su familia, y sobre algunas de las circunstancias significadas de su existencia. El estudio sobre Alonso Álvarez, que constituía la segunda parte de El Loaysa de «El celoso extremeño». Estudio históricoliterario (Sevilla, 1901), fue unánimemente celebrado. Sin embargo, a nadie convenció la hipótesis de identificación de Loaysa con el poeta Alonso Álvarez, ensayo que representaba la tercera y última parte del volumen $^{33}$. Veinticinco años después volvió a editar la biografía, sin las notas y sin el apéndice documental, en una de sus obras de mayor popularidad, la Miscelánea de Andalucía ${ }^{34}$.

31. Lasso de la Vega, 1871, p. 182.

32. Citada en Rayego Gutiérrez, 2002, p. 136.

33. Así concluía su reseña José María Asensio: «Como el trabajo lo merecía, y era punto verdaderamente curioso, me decidí a indagar la opinión de algunos aficionados de reputación conocida, antes de consignar la mía, y en todos encontré igual juicio: el libro del Sr. Rodríguez Marín es una verdadera joya por su erudición, por su lenguaje, por todas sus condiciones literarias; pero en su última parte no convence, no demuestra, a pesar de sus esfuerzos y de su ingenio, que Alonso Álvarez de Soria, poeta y tuerto, sirviera de tipo a Cervantes para trazar el Loaysa del Celoso extremeñom (Asensio, 1903, p. 445). Una perfecta síntesis de las reprobaciones que tuvo la hipótesis de Rodríguez Marín puede leerse en Lara Garrido, 1987, p. 10, n. 1.

34. Rodríguez Marín, 1927, pp. 9-121. 
Los documentos encontrados por Rodríguez Marín en el Archivo de Protocolos de Sevilla y en los archivos parroquiales vinieron a certificar los hechos que a continuación se exponen de forma sumaria. La partida de bautismo hallada en la parroquia de San Vicente de Sevilla probó que Alonso Álvarez de Soria había sido bautizado el dos de septiembre de 1573 , sin que sepamos a ciencia cierta quién fue su madre, aunque a continuación propongamos una conjetura muy probable. Fue hijo de Luis Álvarez de Soria, un comerciante de origen converso que había hecho fortuna del negocio con América ${ }^{35}$, como muchos de su linaje asentados en Sevilla ${ }^{36}$. Este había tenido un hijo en Santa Fe, en la Nueva Granada, con el que regresó a Sevilla en 1567. Poco después, don Luis entró a formar parte del cabildo de la ciudad al obtener el título de jurado ${ }^{37}$, cargo con el que se mencionaba en la semblanza del poeta de la Miscelánea citada por Gallardo («hijo de un jurado del mismo nombre ${ }^{38}$ ). El padre se casó en 1575 con doña Bernardina de Salazar y murió sin testar el once de octubre de $1593^{39}$, circunstancia que supuso años de pleitos y reclamaciones para Alonso y sus hermanos por los derechos de su herencia, ya que eran hijos naturales de distintas madres.

En abril de 1595 estuvo en la cárcel, aunque no se conoce la causa de la prisión. Desde allí solicita una autorización judicial para redimir parte de un tributo con el fin de poder ir a las Indias, voluntad que declara en el propio escrito. El teniente de asistente se lo negó en primera instancia; pero el once de abril presentó un escrito de apelación ante el regente y los oidores. Finalmente, entre los días cinco y ocho de mayo, fuera ya de la cárcel, se le concedió la redención del tributo, y, por consiguiente, tenía vía libre para embarcar y partir a las Indias con mercaderías ${ }^{40}$. Rodríguez Marín dio por sentado que cruzó el Atlántico, pero parece muy improbable que pudiera estar de vuelta en Sevilla en octubre de 1596, fecha en la que hay indicios de su presencia en la ciudad. Cabe añadir que no consta tampoco su nombre, como hemos podido comprobar, en los libros de pasajeros entre los años de 1577 y 1620 (Archivo General de Indias (AGI): Contratación, 5538, L. 2 [1577-1620]).

El documento más importante de los publicados por Rodríguez Marín es el escrito de reclamación que Alonso Álvarez de Soria redactó en la cárcel, recogido en el oficio núm. 7 del escribano Melchor de León, con fecha 4 de febrero de 1603 (fols. 368 y 369) (1. $^{4}$ Por este documento sabemos que era vecino de la collación de San Vicente y que estaba preso en la cárcel de la Real Audiencia por una sentencia que lo

35. Pike, 1978.

36. Sánchez-Cid, 2017.

37. Rodríguez Marín, 1901, p. 103.

38. Adviértase que el autor de la Miscelánea se equivocaba: su padre compartía nombre con su hijo Luis, no con Alonso.

39. Rodríguez Marín, 1901, pp. 329-330 (docs. viII-X).

40. Rodríguez Marín, 1901, pp. 335-336 (docs. XVI-XVII).

41. Rodríguez Marín, 1901, pp. 335-336 (docs. XVI-XVII). 
había involucrado en la muerte de Gonzalo Álvarez, y por la que había cumplido

el tenor de la sentencia contra mí dada en el dicho pleito la cual fue contra mí rigurosa respecto de no ser como yo no fui culpante en la muerte de dicho Gonzalo Álvarez difunto, como del dicho pleito más largo consta e parece.

De las palabras de Alonso Álvarez en la reclamación se deduce que en la sentencia quedó probado que no participó directamente en la muerte de Gonzalo Álvarez, pero el empeño del fiscal en condenarlo le había acumulado nuevas causas «en que dice que soy culpado en ella y me va haciendo muchas molestias y vejaciones». De este pleito, lamentablemente, no hemos podido averiguar nada más que lo que consta en el protocolo publicado fielmente por Rodríguez Marín. Mediante el escrito de reclamación solicitaba que fuera revisada la causa y se exculpaba de cualquier responsabilidad en ella. Además, protestaba públicamente porque había sido lesionado el derecho de estar acogido a sagrado cuando lo apresaron en el interior de la iglesia de la Magdalena de Sevilla.

Este es el último documento conocido de la vida del poeta. Por desgracia, los pleitos, sentencias y procesos de la Real Audiencia de Sevilla $^{42}$ concernientes a ese año y siguientes se perdieron en el incendio del archivo de 1918; así pues, no queda ningún documento judicial de la instrucción del caso en el Archivo Histórico Provincial de Sevilla, donde hoy se conservan los de la Real Audiencia y Audiencia Territorial. Ningún otro protocolo relacionado con la reclamación de Alonso Álvarez hemos encontrado en el oficio número siete (sign. 18401) durante el periodo en que fueron escribanos públicos Melchor de León y Juan de Santamaría.

Lo ofrecido en este escrito de reclamación permite plantear una conjetura sobre las causas de la ejecución del poeta. Su probable participación indirecta en la muerte del tal Gonzalo Álvarez sí parece una razón fundada para que fuera condenado a la pena capital. Rodríguez Marín, persuadido por la verosimilitud de la información contenida en la Miscelánea de la Biblioteca Capitular, creyó, en buena lógica, que Alonso Álvarez había sido excarcelado, o se había fugado ${ }^{43}$, y fue apresado después de junio de 1603 en la iglesia de Santa Ana, en Triana, como relataba la Miscelánea, cuando ya era asistente don Bernardino de Avellaneda. Ciertamente, en febrero de 1603, fecha del escrito, era aún asistente de la ciudad don Juan Manuel de Mendoza, marqués de Montesclaros, que había sido nombrado en 1601.

En caso de que hubiera sido condenado a muerte por su implicación en los hechos relacionados con la muerte de Gonzalo Álvarez, la sentencia, de ordinario, se habría sustanciado inmediatamente, a no ser

42. Tenorio y Cerero, 1924.

43. Rodríguez Marín, 1901, p. 192. 
que apelaciones y reclamaciones como la citada dilataran la ejecución hasta el tiempo en el que el nuevo asistente era ya don Bernardino de Avellaneda, a quien apela el soneto de Juan de la Cueva para que le conmutara la pena capital. Como hemos probado, el texto que señala como causa de su muerte los improperios que el poeta dedicó al asistente y que sostiene que fue apresado en Santa Ana se redactó después de 1621 y, por tanto, no es de extrañar que su autor confundiera los detalles de los acontecimientos, pues sería demasiada casualidad, o más bien torpeza, que Alonso Álvarez, lidiador ahigadado, incurriera dos veces en el mismo error de dejarse atrapar primero en la iglesia de la Magdalena y después en la de Triana, máxime cuando había podido comprobar que la justicia hispalense hacía caso omiso de los derechos que asistían a los retraídos, como denuncia en el escrito de reclamación.

Después del escrito de cuatro de febrero de 1603 se pierde completamente el rastro documental del poeta, siniestro indicio de que su muerte, como se ha creído, debió de producirse unos meses después ${ }^{44}$. El libro $1^{\circ}$ de defunciones del archivo parroquial de San Vicente, donde fue bautizado y de donde era vecino, recoge los fallecimientos entre 1597 y 1628; pero no registra los años que van de 1603 a 1605. Era

44. Sobre miembros de la familia de Alonso Álvarez de Soria hay en el Archivo Histórico Provincial de Sevilla una serie de documentos inéditos, próximos a las fechas probables de su muerte, que he podido leer con el auxilio y gentileza del historiador Javier Sánchez-Cid. A continuación se numeran y extractan con su correspondiente referencia (legajo / oficio / año / libro / folio):

4193-6-1602-3ำ (II)- $1312 \mathrm{r}^{\circ}$

$\mathrm{P}^{\circ}$ Cano Santoyana, v ${ }^{\circ} \mathrm{S}^{\mathrm{a}}, \mathrm{S}$ Miguel, como principal; $\mathrm{Hd}^{\circ}$ Álvarez de Soria, jurado y v ${ }^{\circ}$ $\mathrm{S}^{\mathrm{a}}$, S Vicente, en la c / de las armas, y otros, como fiadores, se obligan con el hospital de S Hermenegildo, llamado del Cardenal, en razón de la mayordomía que se le concede al primero de los citados. 17 y18 septiembre 1602

6126-10-1603-2 ${ }^{\circ}-1029 \mathrm{r}^{\circ}$ y $1075 \mathrm{r}^{\circ}$

Diego Núñez de Obando y $\mathrm{D}^{\mathrm{a}}$ Isabel de Figueroa, su mujer; el capt ${ }^{\mathrm{a}} \mathrm{n}$ D Sebastián de Obando y $\mathrm{D}^{\mathrm{a}}$ Inés de Guzmán y Figueroa, su mujer, $\mathrm{v}^{\mathrm{o}} \mathrm{s} \mathrm{S}^{\mathrm{a}}, \mathrm{St}^{\mathrm{a}}$ Marina, se obligan a sacar en paz y a salvo a $\mathrm{Hd}^{\circ}$ Álvarez de Soria, jurado $\mathrm{y} \mathrm{v}^{\circ} \mathrm{S}^{\mathrm{a}}$, de la fianza que dio, a pesar de que por ella lo habían ejecutado. Sábado, 7 junio 1603.

En 1075 r $^{\circ} \mathrm{Hd}^{\circ}$ Álvarez de Soria y Diego Núñez de Obando, jurado de $\mathrm{S}^{\mathrm{a}}$, se dan por libres y quitos de todas las cuentas que han tenido. Martes, 10 de junio de 1603.

6136-10-1605-4ำ-743 $\mathrm{r}^{\circ}$

$\mathrm{Al}^{\circ}$ de Valladares, $\mathrm{v}^{\mathrm{o}} \mathrm{S}^{\mathrm{a}}, \mathrm{S}$ Lor ${ }^{\circ}$, en nombre de Luis Álvarez de Soria, mi cuñado, $\mathrm{e}^{\mathrm{o}}$ del Rey y not ${ }^{\circ}$ púb $^{\circ}$ del juzgado eclesiástico de Cartagena de Indias, por poder ante Juan de Meneses, $\mathrm{e}^{\mathrm{o}} \mathrm{p}^{\mathrm{o}}$ de Cartagena, en 23 agosto 1601, vendo al sr D Fc de Salazar, $\mathrm{v}^{\circ} \mathrm{S}^{\mathrm{a}}$, $8282 \mathrm{mrs} \mathrm{de}_{\text {trib }}{ }^{\mathrm{o}}$ y censo [...] que el dr Luis de Medina, $\mathrm{v}^{\mathrm{o}} \mathrm{S}^{\mathrm{a}}$, S Vicente, como principal deudor, $\mathrm{y} \mathrm{Hd}^{\circ}$ Álvarez de Soria, jurado $\mathrm{y} \mathrm{v}^{\circ} \mathrm{S}^{\mathrm{a}}$, S Vicente, como fiador, vendieron a Luis Álvarez de Soria, situado sobre las rentas del almojarifazgo mayor de $\mathrm{S}^{\mathrm{a}}$. Leonor de Soria, mujer de $\mathrm{Al}^{\circ}$ de Valladares aceptó la escrt ${ }^{\mathrm{a}}$. 28 agosto 1605 . El poder en fol. $744 \mathrm{r}^{\circ}$ : Luis Álvarez de Soria [...] doy poder al jurado $\mathrm{Hd}^{\circ}$ Álvarez de Soria, mi tío; Juan de Mesa; Gaspar de León Hurtado, $\mathrm{e}^{\mathrm{o}} \mathrm{p}^{\mathrm{o}}$, y Al $\mathrm{Al}^{\mathrm{o}}$ de Valladares, mi cuñado, $\mathrm{e}^{\mathrm{o}} \mathrm{de} \mathrm{S} \mathrm{Mjd}$, todos $\mathrm{v}^{\mathrm{o}} \mathrm{s}$ de $\mathrm{S}^{\mathrm{a}}$, para vender dos tributos que tengo en la ciudad de $\mathrm{S}^{\mathrm{a}} . \mathrm{Al}^{\circ}$ de Valladares era administrador de $\mathrm{D} \mathrm{Fc}{ }^{\circ}$ de Salazar y en el fol. $749 \mathrm{r}^{\circ}$ le rinde cuentas. Doct ${ }^{\circ}$ s relacionados en fols. $773 \mathrm{r}^{\circ}$ y $776 \mathrm{r}^{\circ}$, otorgados por Juan de Mesa y D Fc ${ }^{\circ}$ de Salazar. 
común que los familiares recogieran el cadáver después del ajusticiamiento y le dieran sepultura en sagrado ${ }^{45}$.

El estudio de Rodríguez Marín incluyó un testimonio más de su muerte, un romance incluido en el manuscrito BNE 3890 (fol. 108r.) que relataba con tintes macabros los pormenores de su ejecución en la horca: «Elevada está Sevilla» ${ }^{46}$. Tiene las características de un romance noticiero que se hace eco del acontecimiento reciente y conmovedor. Autores de anales y memorias de la historia local de Sevilla, como Francisco de Ariño en los Sucesos, incorporaron este género de poemas en sus relaciones con el fin de ofrecer el testimonio popular del efecto emocional que el acontecimiento había producido en la ciudad.

Al margen de la fantasía desbordada de Rodríguez Marín para reconstruir la biografía del ruiseñor del hampa, su ensayo fue decisivo también para comenzar a recopilar el corpus poético de Alonso Álvarez ${ }^{47}$. Editó cuatro de los sonetos de la contienda con Cristóbal Flores que recogía el manuscrito de la Biblioteca Nacional 3890, que años después amplió considerablemente con nuevos testimonios Lara Garrido ${ }^{48}$. Además, le atribuyó sin demasiadas pruebas de convicción algunas de los poemas satíricos que se compusieron con motivo del recibimiento en Sevilla a la marquesa de Denia en $1599^{49}$ y de la llegada de Lope a la misma ciudad en $1602^{50}$.

De ciertas alusiones contenidas en los desafíos en verso que Álvarez de Soria mantuvo con Cristóbal Flores dedujo Rodríguez Marín alguna conjetura plausible. Al tratar sobre la madre del poeta, escribió:

Quién fuera la madre de este niño no me consta, aun habiendo pretendido con mucha diligencia averiguarlo; pero de su alcurnia algo se puede rastrear, por los sonetos de cierto poeta maldiciente, de los cuales trataré en el lugar oportuno. Debió de ser de raza morisca, aunque jamás hubiese vendido alejijas ni alcuzcuz, contra lo que había de afirmar, andando los años el tal poeta ${ }^{51}$.

La sospecha que no pudo averiguar Rodríguez Marín quizá quede confirmada por un protocolo del oficio 19 del Archivo Histórico

45. Sin que acertemos a saber por qué, Rodríguez Marín (1901, p. 201) piensa que fue descuartizado después de su ejecución.

46. Véase la excelente lectura e interpretación que hace Lara Garrido (1987, pp. 1417) a la luz de la teoría social de Foucault.

47. Sobre la biografía de Rodríguez Marín, Escobar (1958) no añadió nada más que lances novelescos injustificados, sin señalar siquiera la deuda contraída con el bachiller de Osuna.

48. Para la transmisión del corpus poético de Álvarez de Soria y la intervención en él de Rodríguez Marín, véase Lara Garrido, 1987, pp. 34-39.

49. Rico, 2011.

50. Solís de los Santos y Rico, 2008.

51. Rodríguez Marín, 1901, p. 100. 
Provincial de Sevilla $\left(\mathrm{Of}^{\circ} 19 ; 1572 \text {; lib. } 3^{\circ} \text {; fol. } 44\right)^{52}$ que extractamos: Benito Díaz, vecino de la ciudad de México, estante en Sevilla, vende a Luis Álvarez de Soria, vecino de Sevilla, en la collación de San Vicente, una esclava morisca, Benita, de dieciocho años, por precio de 1055 reales. El documento está fechado el 24 de mayo de 1572. Así pues, las insinuaciones de Cristóbal Flores en sus versos ${ }^{53}$ parecen corroboradas por este nuevo documento; todo apunta a que la esclava morisca llamada Benita alumbró a Alonso Álvarez meses después de ser comprada por Luis Álvarez de Soria, quien cristianó a su hijo en septiembre de 1573.

También infirió de los lances en verso con Cristóbal Flores que se había dedicado a la farándula, pero de ello no hemos encontrado constancia documental. El Diccionario biográfico de actores del teatro clásico españolno registra ningún Alonso Álvarez que coincida con la cronología de la vida del poeta ${ }^{54}$.

\section{Las fuentes históricas: sin noticias de la muerte de Alonso Álvarez}

Frente a las noticias de la sentencia a muerte y de la ejecución de Alonso Álvarez que nos han proporcionado las fuentes literarias examinadas, resulta poco comprensible que no registren absolutamente nada sobre el caso las crónicas, anales, memorias, efemérides o avisos, modalidades historiográficas muy cultivadas en Sevilla desde finales del siglo XVI, cuyo método consistía en seleccionar los acontecimientos más relevantes sucedidos en los años de un periodo. Especialmente pertinente para tal indagación son las memorias del jesuita Pedro de León (1545-1632), cuya labor de socorro espiritual a los condenados de Sevilla quedó reflejada en un índice de los ajusticiados que él asistió en la cárcel real entre los años 1578 y 1616, con algunos paréntesis cronológicos motivados por su ausencia de la ciudad en otras misiones de la Compañía. Conviene advertir que la obra del misionero jesuita es un relato incompleto, no es una historia exhaustiva de la delincuencia hispalense que registre todos los casos sucedidos en Sevilla. Él mismo declara que solo recoge los ajusticiados que él auxilió en la cárcel real donde estaba Alonso Álvarez en febrero de 1603- y en alguna ocasión a los detenidos por la Santa Hermandad en despoblado. Por otro lado,

52. Expreso mi más sincero agradecimiento al historiador Javier Sánchez-Cid que tenía entre sus fichas el apunte de este protocolo y me lo comunicó generosa y desinteresadamente.

53. Uno de los sonetos de Cristóbal Flores contra Alonso Álvarez comenzaba deslizando la injuria sobre el origen morisco de su madre y judeoconverso del padre: «Si dice que su madre no fue mora, / miente Alonsillo el tuerto, y no lo entiende, / y su padre niega que desciende / del pueblo ingrato que adoró la Tora». Estos versos dieron a entender a Rodríguez Marín (1901, p. 186) lo que el documento citado del AHPs permitiría tal vez avalar.

54. El DICAT registra después de 1650 un Alonso, apodado el tuerto, que asistió a una comida con actores en el Palacio del Buen Retiro. Simón San Mateo, apodado El Tuerto, del que hay documentos entre 1673 y 1692. Fue actor, autor y guardarropa. Finalmente, recoge datos de Diego Santa Cruz Caballero, también apodado El Tuerto, del que se han conservado testimonios desde 1656 a 1679. 
en ocasiones, el padre León evoca algunos hechos en los que no había participado, pero cuya significación le permitía establecer algunas analogías con los anotados por él. Además, consta por algunas de las obras que a continuación vamos a mencionar que hubo otros condenados que Pedro León no certificó. El jesuita estuvo en Sevilla al menos hasta el 19 de abril de 1603, día en el que asiste a Juan Moreno, "ahorcado en Triana por una muerte y otros delitos» ${ }^{55}$. Después partió con el padre Miguel de Escobar a la misión de Lebrija, Trebujena y Chipiona, de la que regresó a los dos meses (probablemente a finales de junio o principios de julio) por orden del Provincial para que «fuese con el padre Alonso de Castro a dar principio a la casa de Probación de Sevilla, en las casas viejas del Marqués de Tarifa [...] Ese mismo año, por el mes de octubre fui a ser Rector de Cádiz» ${ }^{56}$. En 1605 y 1606 estuvo en Fregenal, de donde regresó a Sevilla en agosto de ese año y asistió a un tal Francisco que quemaron. A partir de 1608 permanecerá de forma ininterrumpida en Sevilla ejerciendo su ministerio en la cárcel real. En suma, son muy pocos los meses de 1603 en que el padre León estuvo en Sevilla asistiendo a los condenados, solo entre enero y abril, meses en los que registra dos ajusticiamientos. En 1604 está en Cádiz, y en los años siguientes en Fregenal hasta su vuelta definitiva a Sevilla en 1608. Cabe pensar, pues, que quizás durante los periodos de ausencia de la ciudad del jesuita, a partir de junio de1603, fecha del nombramiento de don Bernardino como asistente, se ejecutara la sentencia.

Los Sucesos de Ariño, que abarcan desde el año 1592 a 1604, nada refieren tampoco de lo sucedido a Alonso Álvarez de Soria. Ariño seleccionó los acontecimientos de modo fragmentario y caprichoso, de tal manera que, principalmente, fue anotando y relatando aquellos sucesos que él estimó que podían concitar el interés social y los que conmovieron a la sociedad; en consecuencia, hizo de su obra el receptáculo de la indignación popular, y expresión de la sátira o del mero sarcasmo contra los poderes públicos. Recogió también algunos romances, coplas o el célebre soneto cervantino «Voto a Dios que me espanta esta grandeza ${ }^{57}$, que oyó en la catedral cuando "entró un poeta fanfarrón y dijo una octava sobre la grandeza del túmulo» ${ }^{58}$. Ariño escribió movido

55. Pedro de León, 1981, p. 541.

56. Pedro de León, 1981, pp. 541-542. De una errónea interpretación del texto de Pedro León y de la omisión del suceso en las memorias del jesuita concluyó Lara Garrido (1987, p. 39, n. 38) que el término ante quem de la ejecución hubo de ser octubre 1603, fecha en la que cree que estaba el padre León de regreso en Sevilla. Pero lo que se ha de entender es que en abril se va con el padre Miguel de Escobara a la misión en Lebrija, Trebujena y Chipiona. A los dos meses regresa para cumplir la orden del Provincial de supervisar las obras de la casa de probación, y, finalmente, parte en octubre a Cádiz. En consecuencia, desde abril de 1603, en Sevilla solo está durante ese año los meses de julio, agosto y septiembre, y no se ocupó del auxilio espiritual de los condenados.

57. Para la importancia de este testimonio en la tradición textual del soneto, véase Solís de los Santos, 2004.

58. Ariño, 1993, p. 105. 
por su voluntad de registrar hechos memorables, entre los que sobresalen algunos asesinatos ocurridos en la ciudad y las ejecuciones de los culpables, como fue el caso del valentón Juan García en 1593, ahorcado y descuartizado después de acorralar a la justicia en una iglesia de Triana y haber matado a uno de los corchetes ${ }^{59}$. Ariño relata la historia de seis ajusticiados, ninguno de ellos en 1603. Sí describe el asesinato el dos de marzo de 1604 de la sobrina del caballero don Pedro de Córdoba y refiere su ejecución ulterior añadiendo que de tal caso se «hicieron los romances siguientes» ${ }^{60}$. Así pues, ni rastro de la muerte de Gonzalo Álvarez, por la que estaba en febrero de 1603 en la cárcel Alonso Álvarez, ni de la ejecución de este.

Mayor pertinencia para nuestro propósito tienen las Noticias y casos memorables de la Ciudad de Sevilla, conservadas en un manuscrito perteneciente a la biblioteca del Conde del Águila ${ }^{61}$, hoy en el Archivo Municipal de Sevilla, que registra treinta y nueve ajusticiados entre 1586 y 1611, y en ninguno de los casos relatados hay algún indicio que se pueda relacionar con la ejecución de Alonso Álvarez. Algunos de los sentenciados incluidos en estas noticias no están en el índice de Pedro de León ${ }^{62}$. En 1603 solo recoge «la desgracia de Parrado, a quien asaetearon sin culpa porque confesó en el tormento y después ajusticiaron a los verdaderos delincuentes que en la horca lo declararon s ${ }^{63}$. De 1604 refiere que el dos de marzo degollaron a don Pedro de Córdoba, caso relatado por Ariño, y la muerte en la hoguera de un viejo sordo y ciego dado al pecado nefando.

Los mismos sucesos en los años de 1603 y 1604 describen las Memorias, editadas por Morales Padrón ${ }^{64}$, integradas en un manuscrito sin título de la Biblioteca Capitular y Colombina de Sevilla (64-7-100) que reúne unos cien documentos. Los datos recogidos en estos anales son pocos y escuetos; no obstante, su autor no pasa por alto los sucesos más truculentos y macabros. Por ejemplo, de 1603 solo se recogen de forma lacónica una riada que quebró el puente y, como el manuscrito que perteneció al conde del Âguila, que “azaetaron a Parrado» ${ }^{65}$. De 1604 se anota, como en Ariño y en las Noticias y casos memorables, que «en 2 de marzo degollaron en la plaza a don Pedro de Cordoba, caballero de Utrera que mató a su sobrina que se quería casar a su disgusto» ${ }^{66}$.

59. Ariño, 1993, p. 17. El mismo suceso fue recogido en las memorias de Pedro de León.

60. Ariño, 1993, p. 120. Una nota del editor, Fabié, indica que no están tales romances en el manuscrito.

61. Archivo Municipal de Sevilla (AMs), subfondo Archivo Histórico-Colecciones, sección XI “Archivo Biblioteca del Conde del Águila», t. 20 [microfilms rollos 61 y 62].

62. Estas comprobaciones fueron realizadas antes con pormenor por Herrera Puga, 1971, p. 293.

63. Noticias y casos memorables..., fols. 33v. y 34.

64. Morales Padrón, 1981.

65. Morales Padrón, 1981, p. 25.

66. Morales Padrón, 1981, p. 26. 
También se hace eco de que en « 2 de julio quemaron al viejo gordo que vendía cartillas en Triana» ${ }^{67}$. En fin, salvo contadas excepciones, estos anales suelen registrar los mismos aciagos sucesos; pero todos ellos omiten lo ocurrido al ruiseñor del hampa. La misma ausencia de datos hemos constatado en otras obras manuscritas del mismo género como las contenidas en los códices de la Biblioteca Capitular y Colombina 59-1-5 (Memorias de diferentes cosas sucedidas en esta muy noble y muy leal ciudad de Sevilla), 59-1-3 (Memorias eclesiásticas y seculares de la muy noble y muy leal ciudad de Sevilla), 57-1-12 (Memorias históricas sevillanas) y 57-6-42 (Papeles varios pertenecientes a la Historia de Sevilla).

Tampoco entre los mil ciento sesenta y dos asientos que recoge el catálogo de la documentación correspondiente a don Bernardino González Delgadillo y Avellaneda (1544-1629) durante el ejercicio de cargos públicos, civiles y militares hay referencia ni alusión al proceso, prisión y ejecución de Alonso Álvarez. Del periodo que ejerció el cargo de asistente de Sevilla (tomó posesión, como se ha dicho, el veintiséis de junio de 1603 y cesó el veintiséis de octubre de 1609), sustituyendo al marqués de Montesclaros, se conservan numerosas reales cédulas y cartas acordadas en que el rey o el Consejo consultan o solicitan información al asistente, el máximo representante de la corona en la ciudad, sobre asuntos que tenían que ver con las causas de personas contra las que había procedido don Bernardino o en las que se le insta a la detención y encarcelamiento de otras por delitos diversos ${ }^{68}$; sin embargo, de la descripción de esos documentos no se puede inferir ninguna referencia a Alonso Álvarez.

En resumidas cuentas, el repaso por este conjunto de obras ha resultado completamente estéril.

\section{Algunas consideraciones sobre la fama y Fortuna del poeta}

El brindis en el Buscón a la memoria del «buen compañero» de los valentones sevillanos y el desvelamiento de su identidad real a partir del siglo XIX fue creando la imagen proverbial de poeta notorio y rufián famoso, (popular y trágica figura» ${ }^{69}$ que dejó «largo recuerdo en los medios hampones y literarios s ${ }^{70}$. Pero nada de lo expuesto permite juzgar que Alonso Álvarez de Soria fue un poeta reconocido y recordado. Del lugar marginal que debió de ocupar en el contexto poético de la Sevilla de su tiempo dan cuenta las propias palabras de la Miscelánea trasladadas por Gallardo, cuyo autor, transcurridas al menos dos décadas desde la muerte del poeta, se esforzaba por dar a conocer a sus contemporáneos la iden-

67. Morales Padrón, 1981, p. 26.

68. Véanse, por ejemplo, los asientos del catálogo 0317 [15 de octubre de 1603]; 0369 [30 de agosto de 1604]; 0526 [9 de septiembre de 1606]; 0593 [15 de mayo de 1607]; 0726 y 0727 [1608] (Campo y Moreno, 2005).

69. Pike, 1978, p. 206.

70. Deleito, 2013, p. 172. 
tidad y la personalidad del primero que empleó los versos de cabo roto en Sevilla. Más significativa aún es su ausencia en los elencos de autores incluidos en las narraciones alegóricas más celebradas de su tiempo, el Viaje de Sannio ${ }^{71}$ y el Viaje del Parnaso (Madrid, 1614). La incredulidad aumenta si se considera, como se ha creído, que los autores de sendos viajes imaginarios tuvieron la oportunidad de conocer al malogrado Alonso. No parece tampoco justificable que Juan de la Cueva hubiera escrito el referido soneto en el que solicita la clemencia del asistente sin el conocimiento directo del condenado y de sus circunstancias; sin embargo, no le dio sitio en la nómina de escritores del Viaje de Sannio.

Juan de la Cueva tuvo entre los poetas epigramáticos hispalenses un gran predicamento. La edad y su trayectoria hicieron de Cueva, probablemente, el referente del grupo de vates contestatarios que se habían situado en los márgenes de los centros de influencia en el campo literario. Su aprecio entre ellos estuvo alimentado por el rechazo que padeció en ocasiones de la élite cultural de la ciudad, donde no se sintió respetado y de la que se autoexcluyó ${ }^{72}$. Rodríguez Marín imaginó que estos inconformistas constituyeron su identidad colegiada en la por él denominada academia de Ochoa, nombre que propuso por entender que tal institución fue abanderada por el dramaturgo sevillano Juan de Ochoa $^{73}$, admirado por Cervantes en el Viaje del Parnaso ${ }^{74}$.

Estos poetas habrían sido los responsables, en opinión de Rodríguez Marín, de los sonetos satíricos dedicados al recibimiento que se dispensó en Sevilla a la marquesa de Denia ${ }^{75}$ en 1599 , y de los que recibieron con ácidas burlas a Lope de Vega en 1602, cuando se instaló en Sevilla, donde llegó tras los pasos de Micaela de Luján. De esta sonetada contra Lope, Rodríguez Marín ${ }^{76}$, sin pruebas suficientes, atribuyó a Álvarez de Soria el diálogo entre valentones que conforma el soneto, «iLope dicen que vino? No es posible». Igualmente conjeturó que el origen de los sonetos dedicados a la de Denia estuvo en alguna reunión académica ${ }^{77}$, y apuntó,

71. Viaje de Sannio se publicó en primera instancia en 1585 , pero veinte años después, le añadió el canto quinto. Para los pormenores de la historia redaccional y editorial de la obra, véase Cebrián, 1990, p. xxv-xxviı.

72. El lugar de Cueva en el grupo sevillano fue expuesto por Prieto, 1987, pp. 501520. El análisis realizado por Valentín Núñez (2000, pp. 267-280) de las epístolas de Juan de la Cueva revela que se sintió excluido durante toda su vida. La misma idea fue subrayada por Escobar, 2011.

73. Rodríguez Marín, 1901, p. 128; 1905, p. 155.

74. No está muy claro que el Juan de Ochoa celebrado en el Viaje del Parnaso (II, v. 8) sea el dramaturgo sevillano (Montero y Romo, 2016, p. 373).

75. Un estado de la cuestión sobre el asunto y testimonios de esa sátira hasta entonces desconocidos pueden verse en Rico, 2011.

76. Rodríguez Marín, 1901, p. 163, y 1905, p. 162.

77. Rodríguez Marín, 1905, p. 15: «Tengo para mí que tanto los siete sonetos copiados como las quintillas que los subsiguen fueron labor hecha para leída en alguna academia poética, y si estoy en lo cierto, ¿cuál pudo ser ésta? Y ¿quiénes los autores de aquéllos? No entraré a tratar de tales cosas, pues sobre que tan lejos no quiero ir, para epístola ya basta, y aun creo que sobra la mitad». 
como posibles autores, a Baltasar del Alcázar, Álvarez de Soria, Juan de la Cueva y Cervantes. No sabemos si esta academia tuvo existencia real, pero de haber tenido vida verdadera convendría mejor llamarla «academia del soneto burlescom, como fue bautizada por Márquez Villanueva ${ }^{78}$. Lo cierto es que nada sabemos de las relaciones de Álvarez de Soria con los miembros de esa hipotética e informal corporación literaria.

Tampoco menciona su nombre el racionero de la catedral Francisco Porras de la Cámara entre los personajes de distinta condición que conformaron la por él llamada Academia de san Vicente. De ella hace relación en el manuscrito de la Biblioteca de Palacio Real (врRм), Іі / 2243 (2), [Papeles satíricos, etc. de Sevilla a finales del XVI], única prueba acreditada hasta hoy de la existencia de una academia dedicada a lo burlesco en Sevilla por esos años ${ }^{79}$. Del testimonio de Porras de la Cámara en varios pasajes de este manuscrito de Palacio que recoge los Escolios, del también poeta sevillano Sáez de Zumeta ${ }^{80}$, y otros cuentecillos denominados burlas hemos tomado la noticia de tal academia, dedicada en exclusiva por lo que se deduce de sus palabras y por los textos que de ella recopila y transmite, a la literatura festiva. La designa con el nombre de Academia de san Vicente, por el lugar en el que se ubica, el barrio del mismo nombre, del que, por cierto, era vecino Alonso Álvarez. Esta academia era frecuentada por los humanistas del entorno de la catedral, como Diego de Ulloa, arcediano de Écija y sobrino del cardenal don Rodrigo de Castro, Sebastián de Astudillo y Fernando de Cepeda, racionero de Sevilla, autores en el mismo manuscrito de una burla (fols. 125r-126v) o broma en forma de cuento dedicada a Mateo Vázquez de Leca, canónigo y arcediano de Carmona. Entre los integrantes de la citada academia se encuentra don Fadrique Enríquez de Rivera, primer marqués de Villanueva del Río. Por esta singular crónica de la literatura burlesca sevillana y por los Escolios contra Juan Baptista Pérez de Juan Sáez de Zumeta desfilan algunos poetas satíricos menores como Diego Martínez de Leyva, quien creemos que es el mismo poeta macarrónico citado por Pacheco en la Sátira apologética en defensa del divino Dueñas o Sátira contra la mala poesía: "Harto más gana Leyva en ensayarse / en la arte macarronea que en la trova». También es nombrado en la Macarronea («ante quidem numerare queamquot Leiva putanas / conciliat) vv. 401-402] $)^{81}$. También concurre Francisco de Pamones, de quien conocemos, por ejemplo, algunos sonetos del manuscrito 3980 de la BNE,

78. Márquez Villanueva, 1987 y 1995.

79. Junto con el profesor José Solís de los Santos preparo la edición de los Escolios contra Juan Baptista Pérez de Juan Sáez de Zumeta incluidos en la relación de Porras de la Cámara donde se alude a los miembros de esta academia. Los Escolios permanecen aún inéditos en tres manuscritos: el вNE 20355 (fol. 265), el врRм, II / 2243 (2) (fol. 71) у el Bus [Biblioteca de Humanidades] RA-158 (fol. 146v).

80. Este códice atribuye Escolios a Juan Sáez de Zumeta y al licenciado Enrique Duarte, conocido principalmente por el prólogo escrito A la memoria de Fernando de Herrera de los preliminares de la edición de Pacheco (1619) de la poesía de Herrera.

81. Montero y Solís de los Santos, 2005. 
que recoge también un buen número de poemas de Alonso Álvarez de Soria $^{82}$ y Juan de Ochoa. El corpus principal de su poesía se encontraba en el perdido códice de la Biblioteca del Palacio Arzobispal de Sevilla, el llamado códice de Barahona o de Pamones, que se ha conservado reproducido en la copia del manuscrito del Consejo RM-5177. Juan de Robles evocó en El culto sevillano al «buen viejo Pamones», por ser el autor de unos sonetos muy artificiosos, de consonantes duplicados, parientes de los sonetos en eco, que concurrieron en una incierta academia, que «se juntaba entonces en casa de cierto personaje» ${ }^{83}$. Cervantes recuerda en el Viaje del Parnaso el gusto de Pamones por esas formas artificiosas: «con quien las musas ojeriza tienen / porque pone sus pies por do ninguno / los puso y con sus nuevas fantasías / mucho más que agradable es importuno» (IV, vv. 419-422).

En los versos de su alegórico viaje Cervantes pasa revista a Ochoa, López del Valle, al propio Pamones y a otros con los que se ha asociado a Alonso Álvarez. Cervantes pudo tener la oportunidad de conocerlo desde que se estableció en Sevilla en 1588, razón por la que su omisión en el Viaje del Parnaso representa una incógnita más, sobre todo, si damos por cierta la noticia de que fue él quien introdujo en Sevilla la décima de cabo roto, artificio métrico tan seductor para Cervantes que llegó a componer con él para los preliminares del Quijote las siete décimas de Urganda la Desconocida, más las dos que pone en boca de Sancho y Rocinante ${ }^{84}$.

Los versos satíricos de la décima atribuida en la Miscelánea a Álvarez de Soria apuntaron a los blancos dilectos de los destemplados poetas sevillanos: Lope ${ }^{85}$ y Arguijo ${ }^{86}$ ( Envió Lope de Ve- / al señor de don Juan de Arguí- / el libro del Peregrí...»), razón de más para relacionarlo con ellos, como hicieron Rodríguez Marín y Adrienne Laskier Martín ${ }^{87}$. Otra cuestión es saber cuándo y cómo pudo escribir Álvarez de Soria la décima: la aprobación del Peregrino en su patria firmada por Gracián Dantisco es de noviembre de 1603; luego, hay que pensar que Lope envió la obra a Juan de Arguijo para que le diera su parecer poco antes, y lo que sabemos es que en febrero de ese año Alonso Álvarez estaba en la cárcel desazonado por la inquina del fiscal de su majestad que lo retenía en prisión con nuevos cargos. Cabría preguntarse si en tales circunstancias tuvo oportunidad de escribir la referida décima.

82. Véanse los datos exactos de la recensio realizada por Lara, 1987, pp. 43-48.

83. Juan de Robles, 1992, p. 177. Nos atrevemos a conjeturar que se trata de la llamada por Porras de la Cámara Academia de san Vicente.

84. Para la noticia más completa sobre los orígenes y evolución de los versos de cabo roto, véase Alatorre, 2007, pp. 350-360.

85. Rico y Solís, 2008.

86. Escobar, Montero, Rico y Solís, 2015.

87. Laskier Martín, 1991, pp. 157-164. 


\section{A MODO DE RECAPITULACIÓN}

Ninguno de los documentos que conocemos sobre la existencia del poeta Alonso Álvarez de Soria permite verificar la fecha y las circunstancias de su muerte. Solo testimonios literarios han transmitido la noticia. El primero de ellos, el sentido recuerdo que le tributan los hampones sevillanos en la siniestra cena del último capítulo del Buscón. También ignoramos cómo pudo tener conocimiento del suceso Quevedo. La correspondencia conservada de Quevedo en la primera década del siglo es muy escasa e irrelevante para el asunto y no hay pruebas documentales de que hubiera estado en Sevilla antes de $1609^{88}$. La segunda fuente es el relato recogido en la Miscelánea que transcribió Gallardo en su Ensayo de una biblioteca de libros raros y curiosos. El texto trasladado por Gallardo fue la piedra de toque que permitió establecer relaciones causales con el soneto ochenta y uno del manuscrito de las Obras de Juan de la Cueva (всC 56-3-4, fol. 119r.), «No des al Febeo Álvarez la muerte / oh, gran don Bernardino, así te veas», y con las composiciones del propio Álvarez. La muerte en el cadalso del poeta y el rigor de la sentencia dictada por el asistente, circunstancias que había revelado la Miscelánea, casaban bien con la deprecación en endecasílabos de Juan de la Cueva, con el romance del propio Álvarez de Soria «cuando le llevaron a ahorcars y con la anónima crónica en verso de su muerte. Pero la Miscelánea, además de no precisar la fecha de la ejecución, incluye algunos datos que lesionan la lógica de lo verosímil, a saber, que la causa de la muerte fue el insulto proferido al asistente o que en otra composición de cabo roto profetizó la muerte en el cadalso de don Rodrigo Calderón. Las referencias literarias citadas son las únicas certidumbres que poseemos sobre el final de su existencia. El repaso sistemático de los anales, avisos, efemérides y todo género de crónicas que seleccionaban los acontecimientos más relevantes sucedidos en Sevilla durante los años en que se pudo producir la muerte de Álvarez de Soria no registran ninguna mención ni indicio del suceso.

En suma, la historia literaria ha fundado una imagen de Alonso Álvarez de Soria sobre el conocimiento incompleto e inexacto de los hechos, sin reparar en las anomalías que entrañaban las hipótesis concebidas por Rodríguez Marín en torno a su vida y su muerte, muchas de las cuales se han aceptado como verdades probadas. El silencio documental a partir de febrero de 1603 representa, en nuestra opinión, el indicio más elocuente, pero solo el indicio, de que su muerte debió de producirse, como se ha venido admitiendo, poco después; pero esta impresión no puede ser más que un juicio provisional.

88. Schwartz, 2004, p. 377. Ni siquiera se puede constatar documentalmente que llegara en el séquito de Felipe iv cuando viajó a Sevilla y Andalucía en 1624 (Plata, 2016). 


\section{Bibliografía}

Alatorre, Antonio, Cuatro ensayos sobre arte poética, México, El Colegio de México, 2007.

Ariño, Francisco de, Sucesos de Sevilla de 1592 a 1604, Sevilla, Ayuntamiento, 1993 (facsímil de la ed. Antonio María Fabié, Sociedad de Bibliófilos Andaluces, Sevilla, 1873).

Asensio, José María, «Reseña de El Loaysa del celoso extremeño», Boletín de la Real Academia, 42, 1903, pp. 442-445.

Bennassar, Bartolomé, La España del Siglo de Oro, Barcelona, Crítica, 1990.

Blecua, José Manuel, (ed.), Francisco de Quevedo, Obra poética, III, Madrid, Castalia, 1999.

Cabo Aseguinolaza, Fernando, (ed.), Francisco de Quevedo, La vida del Buscón, Madrid, RAE, 2011.

Campo Hernán, María del Pilar del, y José María Moreno Martín, Catálogo de documentos de Bernardino de Avellaneda en el Archivo del conde de Orgaz (15701636), Madrid, Museo Naval, 2005.

Cebrián, José (ed.), Juan de la Cueva, Viage de Sannio, Miraguano, Madrid, 1990.

Cotarelo, Emilio, El conde de Villamediana. Estudio biográfico-crítico con varias poesías inéditas del mismo, Madrid, Sucesores de Rivadeneyra, 1886.

Deleito y Piñuela, José, La mala vida en la España en la España de Felipe IV, Madrid, Alianza, 2013.

Díaz-Migoyo, Gonzalo, “Las fechas en y de El Buscón de Quevedo», Hispanic Review, 48, 1980, pp. 171-193.

Duque de Estrada, Diego, Comentarios del desengañado de sí mismo, ed. Henry Ettinghausen, Madrid, Castalia, 1982.

Escobar, Juan Antonio, Alonso Alvarez de Soria, biografía amarga de un poeta hampón de la Sevilla del siglo XvI, Madrid, La Xilográfica, 1958.

Escobar Borrego, Francisco Javier, "Juan de la Cueva, artifex exclusus: un poeta en los márgenes del Parnaso sevillano: a propósito del Viaje de Sanniom, en Compostella Aurea. Actas del viII Congreso de la Asociación Internacional Siglo de Oro (AISo), coord. Antonio Azaustre Galiana y Santiago Fernández Mosquera, Santiago de Compostela, Universidad, 2011, vol. 1, pp. 263-270.

Escobar Borrego, Francisco, Juan Montero Delgado, José Manuel Rico García, y José Solís de los Santos, «Juan de Arguijo y la Sevilla del Siglo de Oro. El contexto literario", en Juan de Arguijo y la Sevilla del Siglo de Oro. Exposición virtual, Sevilla, Secretariado de Publicaciones de la Universidad de Sevilla, Biblioteca de la Universidad, Instituto Andaluz del Patrimonio Histórico, 2015, pp. 63-78.

Fernández Guerra, Aureliano, Noticias de un precioso códice de la Biblioteca Colombina: algunos datos nuevos para ilustrar el "Quijote»; varios rasgos ya conocidos, ya inéditos de Cervantes, Cetina, Salcedo, Chaves y el bachiller Engrava, Madrid, Imprenta y Estereotipia de M. Rivadeneyra, 1864.

Ferrer Valls, Teresa, Diccionario biográfico de actores del teatro clásico español (DICAT), Kassel, Reichemberger, 2008.

Gallardo, Bartolomé José, Ensayo de una biblioteca española de libros raros y curiosos, Madrid, Imprenta y Estereotipia de M. Rivadeneyra, 1863.

Gallardo, Bartolomé José, Ensayo de una biblioteca española de libros raros y curiosos, Madrid, Imprenta y Estereotipia de M. Rivadeneyra, 1866, vol. 2. 
Herrera Puga, Pedro, Sociedad y delincuencia en el Siglo de Oro. Aspectos de la vida sevillana en los siglos XVI y XVII, Granada, Universidad, 1971.

Lara Garrido, José, Alonso Alvarez de Soria, ruiseñor del hampa (vida y literatura de un barroco marginal), Málaga, Litoral, 1987.

Laskier Martín, Adrienne, Cervantes and the burlesque sonnet, Berkeley, University of California, 1991.

Lasso de la Vega, Ángel, Historia y juicio crítico de la escuela poética sevillana en los siglos XVI y XVII, Madrid, Viuda e Hijos de Galiano, 1871.

Lázaro Carreter, Fernando, "Originalidad del Buscón», en Homenaje a Dámaso Alonso, Madrid, Gredos, 1961, vol. 2, pp. 319-337.

León, Pedro de, Grandeza y miseria en Andalucía. Testimonio de una encrucijada histórica (1578-1616), ed. Pedro Herrera Puga, Granada, Facultad de Teología, 1981.

Márquez Villanueva, Francisco, «El mundo literario de los académicos de $\mathrm{La}$ Argamasilla», La Torre, 1, 1987, pp. 9-43, (reeditado en, Trabajos y días cervantinos, Alcalá de Henares, Centro de Estudios Cervantinos, 1995, pp. 115-156).

Méndez Bejarano, Mario, Diccionario de Escritores, Maestros y Oradores de Sevilla y su actual provincia, Sevilla, Padilla Libros, 1989 (ed. facsímil de la ed. Tipografía Gironés, Sevilla, 1922-1925).

Mérimée, Ernest, Essai sur la vie et les auvres de Francisco de Quevedo, Paris, Alphonse Picard, 1886.

Montero, Juan y José Solís de los Santos, «La macarronea sevillana del licenciado Francisco Pachecom, en Dejar hablar a los textos. Homenaje al profesor Francisco Márquez Villanueva, ed. Pedro M. Piñero Ramírez, Sevilla, Fundación Machado y Universidad de Sevilla, 2005, vol. 1, pp. 637-666.

Montero Reguera, José y Fernando Romo Feito, (ed.), Miguel de Cervantes, Viaje del Parnaso, Madrid, RAE, 2016.

Morales Padrón, Francisco, (ed.), Memorias de Sevilla (1600-1678), Córdoba, Monte de Piedad y Caja de Ahorros de Córdoba, 1981.

Noticias y casos memorables de la Ciudad de Sevilla, Ms. Archivo Municipal de Sevilla (AMs), subfondo Archivo Histórico-Colecciones, sección XI «Archivo Biblioteca del Conde del Águila», t. 20 [microfilms rollos 61 y 62].

Núñez Rivera, Valentín, “Y vivo solo y casi en un destierro: Juan de la Cueva en sus epístolas poéticas», en La epístola. V Encuentro Internacional sobre Poesía del Siglo de Oro: (Universidad de Sevilla y Córdoba, 23-26 de noviembre de 1998 / organizado por el Grupo de Investigación P.A.S.o. (Poesía Andaluza del Siglo de Oro) ed. Begoña López Bueno, Sevilla, Universidad, 2000, pp. 257-294.

Plata, Fernando, «Risas de ida y vuelta: León de Arce y Quevedo de viaje a Andalucía), La Perinola, 20, 2016, pp. 157-202.

Prieto, Antonio, La poesía española del siglo XVI, II. Aquel valor que respetó el olvido, Madrid, Cátedra, 1987.

Rayego Gutiérrez, Joaquín, Vida y personalidad de don Francisco Rodríguez Marín, "Bachiller de Osuna», Sevilla, Diputación, 2002.

Reyes Cano, José María, “Juan de la Cueva de las Cuevas», en Diccionario filológico de literatura española. Siglo XVI, dir. Pablo Jauralde, Madrid, Castalia, 2009, pp. 334-342.

Rico García, José Manuel y José Solís de los Santos, «La sonetada a Lope del Cartapacio de Palomo (Biblioteca Central del csic, ms. Rм 3857)», Anuario Lope de Vega, 14, 2008, pp. 235-268.

Rico García, José Manuel, «La sátira civil en verso en la Sevilla del Siglo de Oro: nuevos datos acerca de los sonetos del recibimiento que Sevilla hizo 
a la Marquesa de Denia», Boletín de la Biblioteca Menéndez Pelayo, 88, 2011. pp. 87-110.

Robles, Juan de El culto sevillano, ed. Alejandro Gómez Camacho, Sevilla, Universidad, 1992.

Rodríguez Marín, Francisco, El Loaysa de «El celoso extremeño». Estudio históricoliterario, Sevilla, Tip. de Francisco de P. Díaz, 1901.

Rodríguez Marín, Francisco, «Discurso Preliminar» a la edición de Rinconete y Cortadillo, 1905 (ed. facsímil publicada bajo el título de Perfiles de la Sevilla Cervantina. Presentación Rogelio Reyes Cano, Sevilla, Ayuntamiento, 1992.)

Rodríguez Marín, Francisco, Miscelánea de Andalucía, Madrid, Páez, 1927.

Rodríguez Moñino, Antonio y María Brey Mariño, Catálogo de los manuscritos poéticos castellanos existentes en la Biblioteca de The Hispanic Society of America (s. $X V$-XVIII), New York, Hispanic Society of America, 1965.

Rozas, Juan Manuel, El conde de Villamediana. Bibliografía y contribución al estudio de sus textos, Madrid, Csic, 1964.

Sánchez-Cid Gori, Francisco Javier, La familia del dramaturgo Felipe Godínez. Un clan judeoconverso en la época de la contrarreforma, Huelva, Universidad, 2017.

Schwartz, Lía, “Quevedo y Rioja, signos de una amistad en el Anacreón castellanom, en Studies in honor of James O. Crosby, ed. Lía Schwartz, Newark, Juan de la Cuesta, 2004, pp. 367-381.

Solís de los Santos, José, “Una edición crítica del soneto "Voto a Dios" de Cervantes», Philologia Hispalensis, 18, 2, 2004, pp. 7-21.

Tenorio y Cerero, Nicolás, Noticia histórica de la Real Audiencia de Sevilla, [s.1.], [s.n.], 1924. 
